\title{
Comparative Infection Progress Analysis of Lettuce big-vein virus and Mirafiori lettuce virus in Lettuce Crops by Developed Molecular Diagnosis Techniques
}

\author{
Jose A. Navarro, Francisco Botella, Antonio Maruhenda, Pedro Sastre, \\ M. Amelia Sánchez-Pina, and Vicente Pallas
}

First and sixth authors: Instituto de Biología Molecular y Celular de Plantas (IBMCP), UPV-CSIC, Avda. dels Tarongers, s/n, 46022 Valencia, Spain; second author: Departamento de Biología Aplicada, Universidad Miguel Hernández, Avda. Ferrocarril, s/n, 03202 Elx, Spain; third and fourth authors: PRIMAFLOR S.A.T., La Estacion 2, Pulpi, 04640 Almeria, Spain; and fifth author: Centro de Edafología y Biología Aplicada del Segura (CEBAS), CSIC, Campus Universitario de Espinardo, P.O. Box 164, 30100 Murcia, Spain. Accepted for publication 2 January 2004.

\begin{abstract}
Navarro, J. A., Botella, F., Maruhenda, A., Sastre, P., Sánchez-Pina, M. A., and Pallas, V. 2004. Comparative infection progress analysis of Lettuce big-vein virus and Mirafiori lettuce virus in lettuce crops by developed molecular diagnosis techniques. Phytopathology 94:470-477.

Nonisotopic molecular dot blot hybridization technique and multiplex reverse transcription-polymerase chain reaction assay for the specific detection of Lettuce big-vein virus (LBVV) and Mirafiori lettuce virus $(\mathrm{MiLV})$ in lettuce tissue were developed. Both procedures were suitable for the specific detection of both viruses in a range of naturally infected

lettuce plants from various Spanish production areas and seven different cultivars. The study of the distribution of both viruses in the plant revealed that the highest concentration of LBVV and MiLV occurred in roots and old leaves, respectively. LBVV infection progress in a lettuce production area was faster than that observed for MiLV. In spite of different rates of virus infection progress, most lettuce plants became infected with both viruses about 100 days posttransplant. The appearance of both viruses in lettuce crops was preceded by a peak in the concentration of resting spores and zoosporangia of the fungus vector Olpidium brassicae in lettuce roots.
\end{abstract}

Big-vein disease of lettuce (Lactuca sativa L.) is an important problem in most established production areas. Young plants that are affected remain small and unmarketable. When infection occurs at a more mature stage, plants develop a characteristic lighter color of the area around leaf veins and leaves become ruffled and misshapen. These symptoms are usually accompanied by a slight reduction in the size of plants while hearting is retarded. Control and diagnosis of lettuce big-vein disease has not, thus far, been possible because characterization of the causal agent has been difficult. Recently, two different viral particles have been isolated from symptomatic lettuce plants: Lettuce big-vein virus (LBVV) and Mirafiori lettuce virus (MiLV). LBVV has a rod-shaped morphology $(12,29)$ and is serologically related to Tobacco stunt virus (10). Recent partial molecular characterization revealed that the LBVV genome consists of two negative-strand RNAs $(26,27)$. This virus has been classified as the type member of the newly unassigned genus Varicosavirus since it was the first virus detected in symptomatic lettuces $(26,27)$. The name of the genus refers to the appearance of chlorotic regions surrounding the vascular tissue that confers the aspect of an anomalous vein enlargement. Moreover, another virus with filamentous particles was isolated from symptomatic lettuces (19) and named MiLV, which is serologically related to Ranunculus white mottle virus and classified as a member of the genus Ophiovirus $(11,13,28)$. This virus consists of a multipartite genome composed of four single-stranded RNAs.

LBVV and MiLV are transmitted by the motile zoospores of the soilborne fungus Olpidium brassicae (Wor.) Dang. (13). The association of these viruses with $O$. brassicae could represent a

Corresponding author: V. Pallas; E-mail address: vpallas@ibmcp.upv.es

Publication no. P-2004-0315-02R

(c) 2004 The American Phytopathological Society serious problem in attempts to avoid propagation of the disease in the field because of a lack of suitable soil chemicals and the long life of the resting spores. Cultural practices to reduce disease losses are limited: crop rotations have not been successful and, although there are some lettuce cultivars that may differ in tolerance, resistant plants are not available $(3,21)$. Fields with recurring and severe big-vein disease histories are not recommended for lettuce planting. When a prospective site is chosen, virus detection in both the irrigation water and the soil, which may be infested with the resting spores of the vector, and even in weeds, which can act as natural reservoir (4), are prerequisites before the planting of lettuce seedlings. Moreover, production areas that are not yet affected are still at risk of the disease via infected transplants. Recently, it has been shown that MiLV, but not LBVV, could induce big-vein symptoms either by mechanical inoculation of a partially purified preparation or by vector transmission to lettuce seedlings (13). However, the presence of two symptomatic lettuce plants, MiLV-negative but LBVV-positive by enzymelinked immunosorbent assay (ELISA), also has been reported in a field survey (20).

In this work, we report the development of a nonisotopic molecular dot blot hybridization technique and a multiplex reverse transcription-polymerase chain reaction (RT-PCR) assay to improve specific detection of both viruses in infected tissue. Furthermore, we studied the distribution of both viruses in lettuce plants monitored by means of dot blot hybridization and performed a comparative study of the infection progress of LBVV, MiLV, and their fungal vector, $O$. brassicae.

\section{MATERIALS AND METHODS}

Plant material. Field-grown lettuce cultivars from Southeast Spain (Almería, Granada, and Murcia) were provided by grupo 
PRIMAFLOR or collected by F. Botella (Universidad Miguel Hernandez [UMH], Alicante). Plants from other Spanish regions (Valencia, Basque country, or Galicia) were supplied by C. Jordá (Universidad Politecnica de Valencia [UPV], Valencia). Several lettuce cultivars, including Iceberg, Hades, Green Oakleaf, Red Oakleaf, Lollo Rosso, Trocadero, Romaine, and Batavia, were obtained from grupo PRIMAFLOR production crops. In the time course analysis of the presence of LBVV and MiLV in lettuce crops, sampling was performed in such a way that all the putative different regions of the production crop were represented; i.e., corners, edges, middle area, and distinct orientation.

Nucleic acid extraction. For dot blot hybridization and RTPCR analyses, nucleic acids were extracted following a procedure that avoids the use of organic solvents, previously adapted from the method described by Dellaporta et al. (6), to viroids (1) and viral RNA $(23,26)$ extractions. Approximately $0.5 \mathrm{~g}$ of fresh leaf tissue was manually homogenized in sealed plastic bags in the presence of $2 \mathrm{ml}$ of extraction buffer $(100 \mathrm{mM}$ Tris- $\mathrm{HCl}, 50 \mathrm{mM}$ EDTA, pH 8.0, $500 \mathrm{mM} \mathrm{NaCl}$, and $10 \mathrm{mM} \beta$-mercaptoethanol). Homogenate aliquots $(0.5 \mathrm{ml})$ (excluding vegetal remains) were transferred to a $1.5-\mathrm{ml}$ tube and incubated with $25 \mu \mathrm{l}$ of $20 \%$ sodium dodecyl sulfate (SDS) at $65^{\circ} \mathrm{C}$ for $20 \mathrm{~min}$. Then, $125 \mu \mathrm{l}$ of $5 \mathrm{M}$ potassium acetate was added and the mixture was maintained at $0^{\circ} \mathrm{C}$ for $20 \mathrm{~min}$. The tubes were centrifuged at $10,000 \mathrm{rpm}$ for $15 \mathrm{~min}$ to remove unwanted plant debris. Nucleic acids were recovered from the supernatant by ethanol precipitation and resuspended in $50 \mu \mathrm{l}$ of sterile water.

For northern blot experiments, total RNA extraction was performed as follows: fresh leaf material $(0.5 \mathrm{~g})$ was ground in liquid nitrogen and added to $2 \mathrm{ml}$ of extraction buffer $(0.35 \mathrm{M}$ glycine, $0.048 \mathrm{M} \mathrm{NaOH}, 0.34 \mathrm{M} \mathrm{NaCl}, 0.034 \mathrm{M}$ EDTA, and 4\% SDS) saturated with phenol (1:1). The mixture was incubated at room temperature for $15 \mathrm{~min}$ with continuous shaking and centrifuged at $10,000 \mathrm{rpm}$ for $10 \mathrm{~min}$. This procedure was repeated once and RNAs were fractionated with $2 \mathrm{M} \mathrm{LiCl}$ overnight at $4^{\circ} \mathrm{C}$. Finally, the insoluble fraction was collected by centrifugation at $8,000 \mathrm{rpm}$ for $20 \mathrm{~min}$ and resuspended in $50 \mu \mathrm{l}$ of sterile water.

Internal control and virus-specific primers. Mitochondrial NADH dehydrogenase subunit 4 (nad4) from lettuce containing two exons separated by a 1,435-bp intron was selected for use as internal control in the multiplex RT-PCR assays. The control primers were designed so that the sense primer (VP 383) was identical to the $3^{\prime}$ extreme of the first exon, except the last $3^{\prime}$ three nucleotides, which matched the first three nucleotides of the second exon. The antisense primer (VP 389) lay totally within the second exon (15). Amplified genomic sequences of LBVV and MiLV were located on viral RNA 2 and 3, respectively. In both cases, a region of the coat protein $(\mathrm{CP})$ gene was selected. The specific sequences of the LBVV and MiLV CP, and nad4 se- quence primers were obtained from GenBank of the National Center for Biotechnology Information (AB050272, AF525935, and L12246, respectively). These primers were designed so that they do not interact with each other, as determined by analysis via the program Genrunner 3.00 (Hastings Software, Hastings-onHudson, NY). Moreover, the primer combination chosen for multiplex RT-PCR assays allowed separation of the expected fragments on $2 \%$ agarose gels. In Table 1 , primer sequence, primer positions, and expected amplified fragment size are given for each template.

Multiplex RT-PCR assay. The RT-PCR assay was carried out in a two-step procedure. For reverse transcription, $2 \mu \mathrm{l}$ of nucleic acid extract, previously heat-denatured in the presence of the oligonucleotides VP 248, VP 287, and VP 383 (10 $\mu \mathrm{M}$ each), was added to the reaction mixture (final volume of $20 \mu \mathrm{l}$ ) containing $1 \times$ RT buffer (provided with the RevertAid H Minus M-MuLV Reverse Transcriptase, Fermentas Life Sciences), 1\% polyvinylpyrrolidone (PVP), 40 units of HPRI RNase inhibitor (Amersham Biosciences, Buckinghamshire, UK), $2.5 \mathrm{mM}$ each dNTP, and 200 units of reverse transcriptase. The reaction was carried out at $45^{\circ} \mathrm{C}$ for $45 \mathrm{~min}$. Multiplex PCR was performed using a reaction mixture containing 1/10 RT mixture; $1 \%$ PVP; $10 \mathrm{mM}$ Tris- $\mathrm{HCl}$, $\mathrm{pH} 8.3 ; 1.5 \mathrm{mM} \mathrm{MgCl}_{2} ; 50 \mathrm{mM} \mathrm{KCl} ; 0.2 \mathrm{mM}$ each dNTP; $10 \mu \mathrm{M}$ each of virus-specific VP 248, VP 249, VP 286, and VP 287 primers; $5 \mu \mathrm{M}$ each of nad4-specific VP 383 and VP 389 primers (specific viral target and amplified product sizes are indicated in Table 1), and 3 units of Taq DNA polymerase (Roche Molecular Biochemicals, Mannheim, Germany). Samples were amplified for 30 cycles with a Gene Amp PCR System 2400 (Perkin-Elmer, Norwalk, CT). Each cycle consisted of denaturation at $95^{\circ} \mathrm{C}$ (30 s), primer annealing at $62^{\circ} \mathrm{C}(30 \mathrm{~s})$, extension at $72^{\circ} \mathrm{C}(40 \mathrm{~s})$, and final extension of $10 \mathrm{~min}$ at $72^{\circ} \mathrm{C}$. To determine the detection limits of the multiplex assay, total nucleic acid extracts from infected lettuce plants were serially diluted in total nucleic acids isolated from uninfected plants and used as templates in multiplex RT-PCR experiments. PCR-amplified products were separated by electrophoresis on a $2 \%$ agarose gel in $1 \times$ TAE buffer $(40 \mathrm{mM}$ Tris-acetate and $1 \mathrm{mM}$ EDTA at $\mathrm{pH} 8.0$ ) for $2 \mathrm{~h}$ at $80 \mathrm{~V}$ and stained with ethidium bromide. Fragment sizes were determined by comparison with 1-kb DNA ladder (Invitrogen Life Technologies).

Construction of virus-specific clones and synthesis of digoxigenin-labeled riboprobes. Genome fragments of cDNA with the complete CP gene of LBVV and MiLV were transcribed and amplified by RT-PCR. First-strand cDNA of the LBVV CP was synthesized from purified RNAs from infected lettuce and isolated as described previously with VP 318 primer and RevertAid H Minus M-MuLV Reverse Transcriptase (Fermentas Life Sciences). For cDNA of MiLV CP, first-strand cDNA was obtained using VP 287 primer. For synthesis of the second strand, aliquots of RT

TABLE 1. Primer sequences and expected size of reverse transcription-polymerase chain reaction products for each primer pair

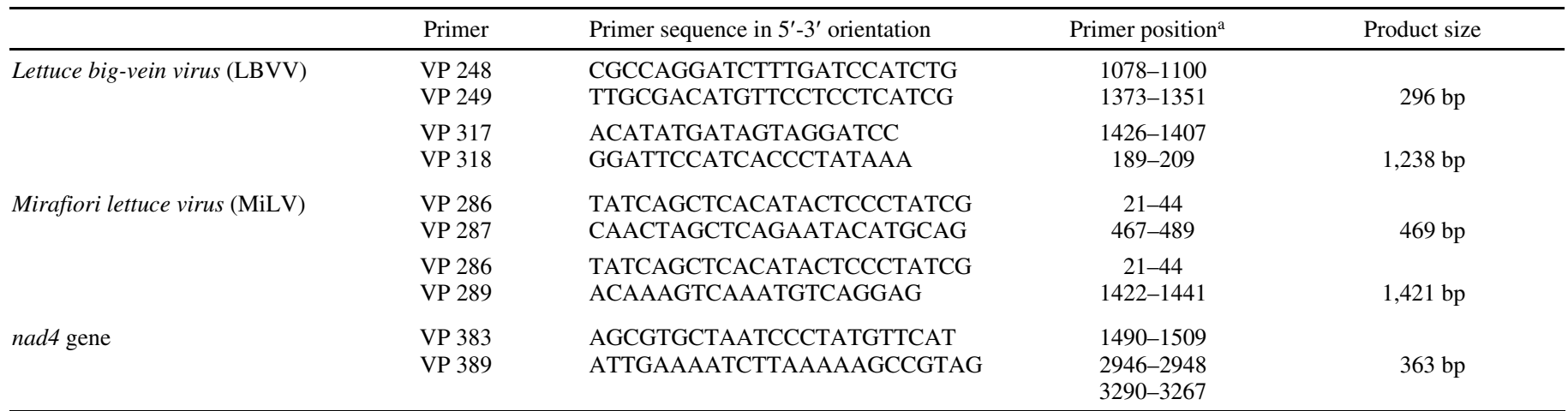

\footnotetext{
a Primer position was numbered after the sequences obtained from GenBank of the National Center for Biotechnology Information (AB050272 for LBVV coat protein [CP], AF525935 for MiLV CP, and L12246 for nad4 gene).
} 
reactions (1/20) were PCR-amplified with VP 317 and VP 286 and Pfu DNA polymerase. A 1,238-bp LBVV-specific product and a 1,420-bp MiLV-specific product were separated by nondenaturing polyacrylamide gel electrophoresis, eluted, and cloned into the EcoRV restriction site of the plasmid Bluescript II KS. After sequencing, these clones were digested with XhoI or XbaI and transcribed with T7 or T3 RNA polymerase in the presence of DIG-11-UTP to obtain digoxigenin (DIG)-labeled viral riboprobes of plus and minus polarities, respectively.

Dot blot hybridization. The nucleic acid samples were denatured by incubation at $60^{\circ} \mathrm{C}$ for $15 \mathrm{~min}$ in the presence of $6 \times \mathrm{SSC}(1 \times \mathrm{SSC}$ is $0.15 \mathrm{M} \mathrm{NaCl}$ plus $0.015 \mathrm{M}$ sodium citrate) and $7.4 \%$ formaldehyde. Each sample $(4 \mu \mathrm{l})$ was applied directly onto the nylon membranes, air dried, and cross-linked by exposure to UV irradiation. The membranes were prehybridized for

TABLE 2. Detection of Lettuce big-vein virus (LBVV) and Mirafiori lettuce virus (MiLV) by dot blot molecular hybridization in several cultivars of lettuce plants collected from different Spanish regions

\begin{tabular}{llccc}
\hline $\begin{array}{l}\text { Lettuce } \\
\text { cultivar }\end{array}$ & Spanish region & $\begin{array}{c}\text { LBVV } \\
\text { infection }\end{array}$ & $\begin{array}{c}\text { MiLV } \\
\text { infection }\end{array}$ & $\begin{array}{c}\text { Mixed } \\
\text { infection }\end{array}$ \\
\hline Batavia & Almería & $6 / 6^{\mathrm{a}}$ & $6 / 6$ & $6 / 6$ \\
Green Oakleaf & Almería & $3 / 3$ & $2 / 3$ & $2 / 3$ \\
Hades & Galicia & $2 / 2$ & $2 / 2$ & $2 / 2$ \\
Iceberg & Almería, Basque country & & & \\
& Valencia & $9 / 10$ & $8 / 10$ & $7 / 10$ \\
Lollo Rosso & Almería & $2 / 3$ & $2 / 3$ & $2 / 3$ \\
Red Oakleaf & Almería & $4 / 4$ & $4 / 4$ & $4 / 4$ \\
Romaine & Murcia & $1 / 3$ & $1 / 3$ & $1 / 3$ \\
Trocadero & Almería & $3 / 3$ & $3 / 3$ & $3 / 3$ \\
\hline
\end{tabular}

${ }^{\mathrm{a}}$ Number of infected samples per number of tested samples. at least $1 \mathrm{~h}$ at $68^{\circ} \mathrm{C}$ and hybridized overnight at the same temperature with DIG-labeled riboprobes (17). Chemiluminescent detection with CSPD reagent as substrate was performed as recommended by the manufacturer (Roche Molecular Biochemicals).

Monitoring $\boldsymbol{O}$. brassicae infection. Fungus infection was microscopically monitored in lettuce roots. Five 1-cm-long slices of roots per plant were randomly taken and stained with Triptan blue, with resting spores and zoosporangia visualized by light microscopy. The quantification of the infection involved measuring the mean number of resting spores and zoosporangia per centimeter.

Statistical analysis. The Pearson correlation coefficient was used to estimate the association of both LBVV and MiLV infection progress, and each virus infection with the big-vein symptoms appearance on lettuce plants for the 2001 to 2002 and 2002 to 2003 periods. Analyse-it software for Microsoft Excel was used.

\section{RESULTS}

LBVV and MiLV detection in lettuce plants by molecular dot blot hybridization. The specificity of viral DIG-labeled RNA transcripts synthesized from the corresponding linearized clones was confirmed by northern blot hybridization experiments. Total RNAs from infected and uninfected lettuce plants were separated by electrophoresis, transferred, and hybridized with either LBVV or MiLV CP riboprobe of both polarities. A single hybridization signal was detected in RNAs from infected tissue. The highest intensity was obtained when RNA preparations were probed with the LBVV or MiLV riboprobes of positive polarity (data not

A

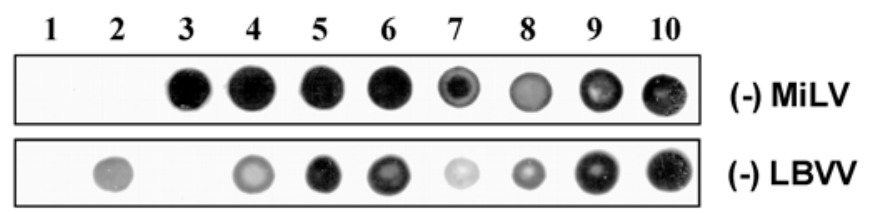

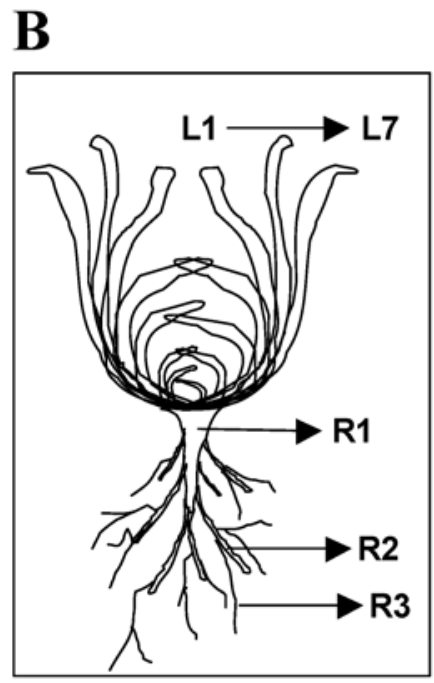

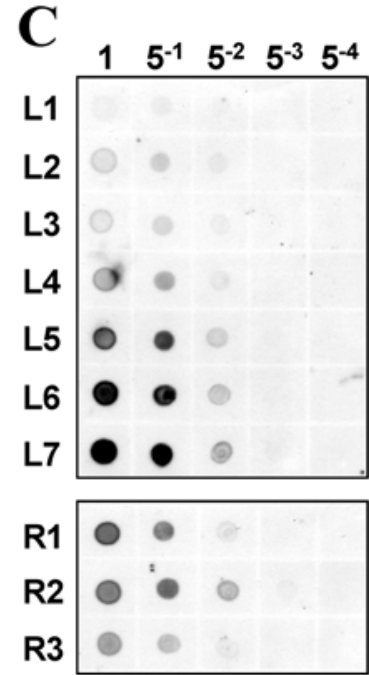

(-) MiLV

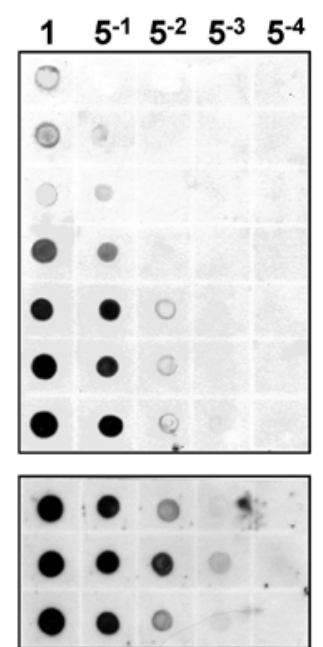

(-) LBVV

Fig. 1. A, Detection of Mirafiori lettuce virus (MiLV) and Lettuce big-vein virus (LBVV) by nonisotopic molecular dot blot hybridization on RNAs from uninfected (lane 1) together with LBVV (lane 2), MiLV (lane 3), and mixed infected (lane 4) Iceberg lettuce cultivar and from Hades (lane 5), Green Oakleaf (lane 6), Red Oakleaf (lane 7), Lollo Rosso (lane 8), Trocadero (lane 9), and Romaine (lane 10) lettuce cultivars. B, Schematic representation of a lettuce plant indicating the tissue selected for LBVV and MiLV distribution analysis. Fresh material included samples from unexpanded (L1) to expanded (L7) leaves, and roots with a diameter of 5 to $12 \mathrm{~mm}, 1$ to $3 \mathrm{~mm}$, and 0.5 to $1 \mathrm{~mm}$ (R1, R2, and R3, respectively). C, Detection of MiLV and LBVV by nonisotopic molecular dot blot hybridization on RNAs from different tissues of a double-infected lettuce plant. Fivefold serial dilution of RNA preparations were applied onto nylon membranes and separately hybridized with each specific riboprobe. Numbers at the top represent the dilutions performed on the initial undiluted sample. Letters with numbers on left as in $\mathbf{B}$. 
shown). The electrophoretic mobility of hybridizing RNAs fit well to the sizes of LBVV RNA 2 or MiLV RNA 3, i.e., RNAs that direct the synthesis of the corresponding CPs $(26,28)$. Consequently, the plus polarity riboprobes of LBVV and MiLV were used for diagnostic purposes. No hybridization signals were observed in total RNA extracted from uninfected plants.

To test whether the riboprobes were suitable for routine and reliable diagnosis of LBVV and MiLV, molecular hybridization experiments were carried out in a dot format using the viral DIGlabeled riboprobes of plus polarity for detecting the minus sense LBVV or MiLV RNA. Extracts were made from a mixture of young and old leaf pieces to avoid false negative results due to any irregular distribution of the virus. Different lettuce cultivars from geographically different Spanish regions were tested (Table 2). Symptomatic plants presented a lighter color of the area around leaf veins and slightly ruffled leaves. A small number of lettuce plants with these symptoms also showed a slight reduction in size. Regardless of the geographic origin or lettuce cultivar, uninfected, single-, and double-infected plants were detected (Table 2). Representative examples of the analysis are shown in Figure 1A. Uninfected, LBVV-, MiLV-, and double-infected 'Iceberg' lettuce samples were analyzed. In no case was cross-reaction of the two riboprobes observed nor was unspecific hybridization signal. Interestingly, both viruses were detected in all cultivars tested (Fig. 1A).

The accumulation of LBVV and MiLV in different tissues was studied by dot blot hybridization. The analysis was performed with three mature lettuce plants of cv. Iceberg that were infected with both viruses and showing big-vein symptoms. Leaves from hearted (L1) to fully expanded (L7) were individually tested while roots were separated according to their diameter (R1 to R3) (Fig. 1B). Fivefold dilution extracts from each selected plant tissue were applied onto nylon membranes. The data obtained from an individual plant are shown in Figure $1 \mathrm{C}$, as the results were similar for all plants tested. The highest titer of LBVV or MiLV was detected in roots or fully expanded leaves, respectively. Moreover, both viral hybridization signals were lower in the youngest leaves, which are usually unexpanded and located inside the head. Therefore, fully expanded leaves were selected to perform the successive analyses.

Amplification of selected viruses and an internal control gene by multiplex RT-PCR. To perform the simultaneous detection of MiLV and LBVV, the specific primer pairs for both lettuce viruses and the control nad4 (15) were added to the same RTPCR mixture. Several oligonucleotide pairs corresponding to different regions of the control nad4 and viral CP sequences were tested. The best results were achieved using the primers VP 248 and VP 249 for LBVV, VP 286 and VP 287 for MiLV, and VP 383 and VP 389 for the control nad4 (Table 1; Fig. 2A). The same nucleic acid preparations analyzed previously by dot blot hybridization were used as templates in multiplex RT-PCR experiments. Control and virus-specific bands that did not vary in concentration or in expected size (Table 1) with respect to the products obtained in single infection were clearly detected in LBVV and MiLV double-infected lettuce plants. The specificity of amplified cDNAs was confirmed by cloning and sequencing the amplified products (data not shown). No additional fragments were observed irrespective of whether the extract came from uninfected or infected lettuce plants. Examples of single- and double-infected lettuce plants with an uninfected control plant analyzed by multiplex RT-PCR are shown in Figure 2B. The results obtained by nonisotopic molecular dot blot hybridization and multiplex RT-PCR were consistent (Figs. 1A and 2B, compare lanes 1 to 4 ).

To determine detection limits for the cocktail of the three pairs of primers in the multiplex RT-PCR assay, extracts from samples infected with both viruses were serially diluted in uninfected extracts and used as template. This approach allowed us to reduce the concentration of virus templates but not of the internal control nad4 mRNA template. LBVV- and MiLV-specific bands were detected up to $2^{-10}$ dilution, corresponding to a fresh weight tissue concentration of $4.8 \mu \mathrm{g} \mathrm{ml}^{-1}$, while the internal control was consistently amplified in each of the samples (Fig. 3A).

To compare this detection limit with that obtained by nonisotopic molecular hybridization, the same samples used for the multiplex RT-PCR assay were applied onto nylon membranes and subjected to hybridization analysis. As observed in Figure 3B, the highest dilution at which viral RNA was still detected for both viruses was $2^{-5}$, corresponding to a fresh weight tissue concentration of $156 \mu \mathrm{g} \mathrm{ml}^{-1}$ and indicating that this technique was 33-fold less sensitive than RT-PCR.

Comparative infection progress analysis of lettuce big-veinassociated viruses and its transmission vector. A temporal study of the appearance in lettuce plants of both associated bigvein viruses was performed in a Spanish production crop (grupo PRIMAFLOR, Almería) by nonisotopic molecular dot blot hybridization. Two-week-old virus-free seedlings from a nursery were transplanted during the 2001 to 2002 and 2002 to 2003 production seasons in a commercial field with a known history of big-vein. Thirty lettuce plants were harvested at 0, 10, 20, 30, 40, 50,80 , and 100 days posttransplanting. Results were quite similar in both periods but the appearance of both viruses (LBVV and MiLV) for the 2001 to 2002 season was 10 days earlier than for the 2002 to 2003 season (compare Fig. 4A and B). The progress of infection of each virus differed significantly $(r=0.64 ; 2$-tailed
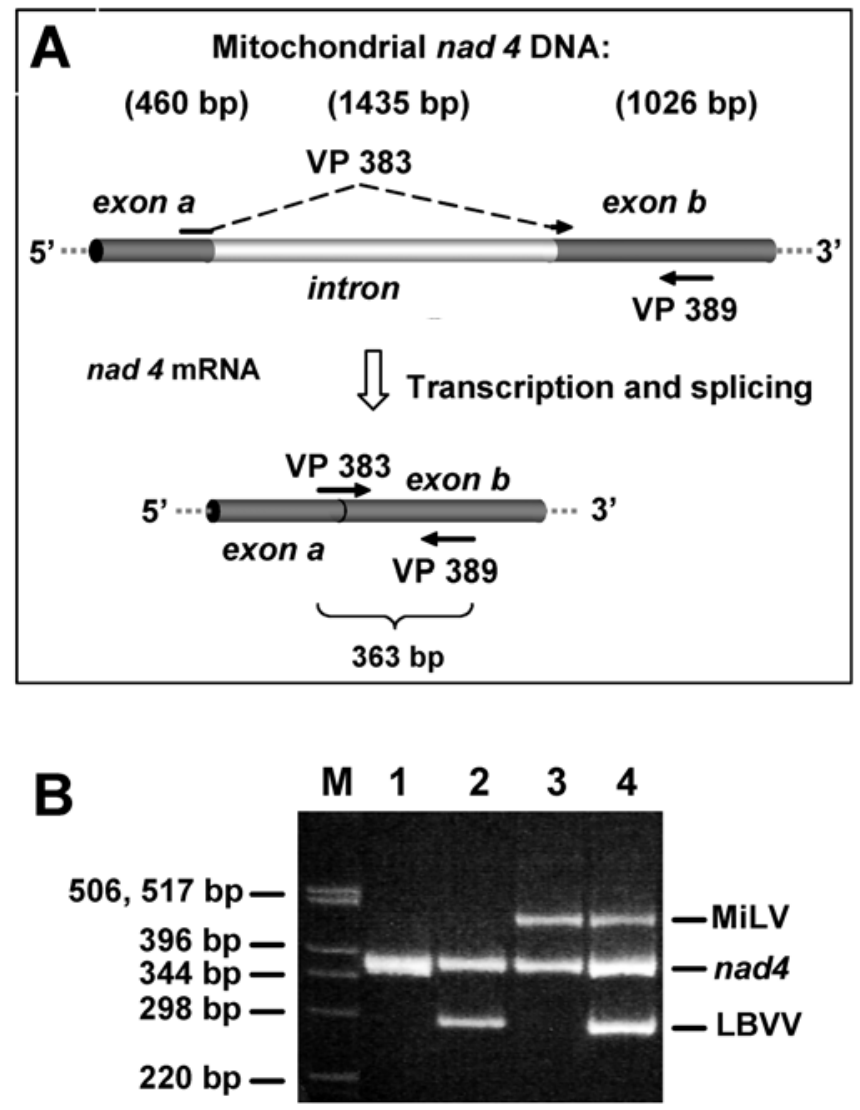

Fig. 2. A, Schematic of the approach used for reverse transcription-polymerase chain reaction (RT-PCR) amplification of a 363-bp cDNA of the control nad4 gene. Locations of internal control oligonucleotides VP 383 and VP 389 are represented by black arrows. The size of the control gene intron and exons are indicated at the top. B, Agarose gel analysis of multiplex RTPCR assays. Representative results from uninfected control (lane 1) together with Lettuce big-vein virus (LBVV) (lane 2), Mirafiori lettuce virus (MiLV) (lane 3), and mixed infected samples (lane 4) are displayed. Virus detected is indicated on the right. Size of DNA molecular marker bands (lane M) is shown on the left. 
$p=0.16$ for the 2001 to 2002 period and $r=0.60 ; 2$-tailed $p=$ 0.28 for the 2002 to 2003 period), with LBVV always detected before MiLV (20 or 30 days posttransplant, Fig. 4A or B, respectively). LBVV quickly spread among the analyzed plants in less than 10 days from initial detection, coinciding with detection of the first MiLV-infected samples (30 or 40 days posttransplanting Fig. 4A or B, respectively). Curiously, the percentage of LBVV- infected plants slightly decreased by the next screening point but then gradually increased. The number of MiLV-infected plants, on the other hand, increased in a more progressive way from its first appearance. At 100 days after transplant, MiLV was detected in 93 and $83 \%$ of analyzed samples for the 2001 to 2002 and 2002 to 2003 periods, respectively. Likewise, LBVV was detected in 100 and $93 \%$ of analyzed lettuce plants for the 2001 to 2002 and

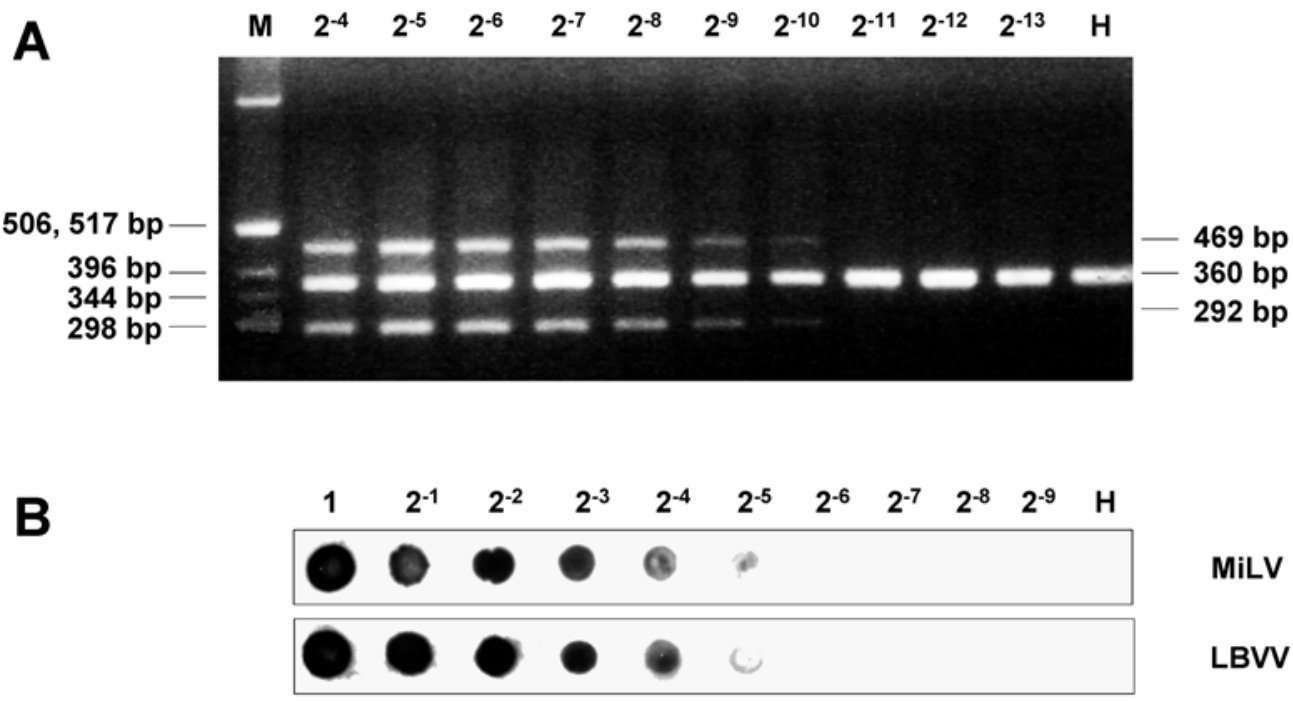

Fig. 3. Estimation of detection limits for Mirafiori lettuce virus (MiLV) and Lettuce big-vein virus (LBVV) by A, multiplex reverse transcription-polymerase chain reaction (RT-PCR) and B, dot blot hybridization. In A, LBVV- and MiLV-specific bands were detected up to $2^{-10}$ dilution, corresponding to a fresh tissue concentration of $4.8 \mu \mathrm{g} \mathrm{ml}^{-1}$. In $\mathbf{B}$, the dilution endpoint with a positive signal was $2^{-5}$, corresponding to a fresh weight tissue concentration of $156 \mu \mathrm{g} \mathrm{m}^{-1}$. Numbers on top indicate the dilution relative to the original undiluted sample. Size of molecular marker bands (lane M) is shown on the left. Lanes H, RNA preparations from uninfected control.
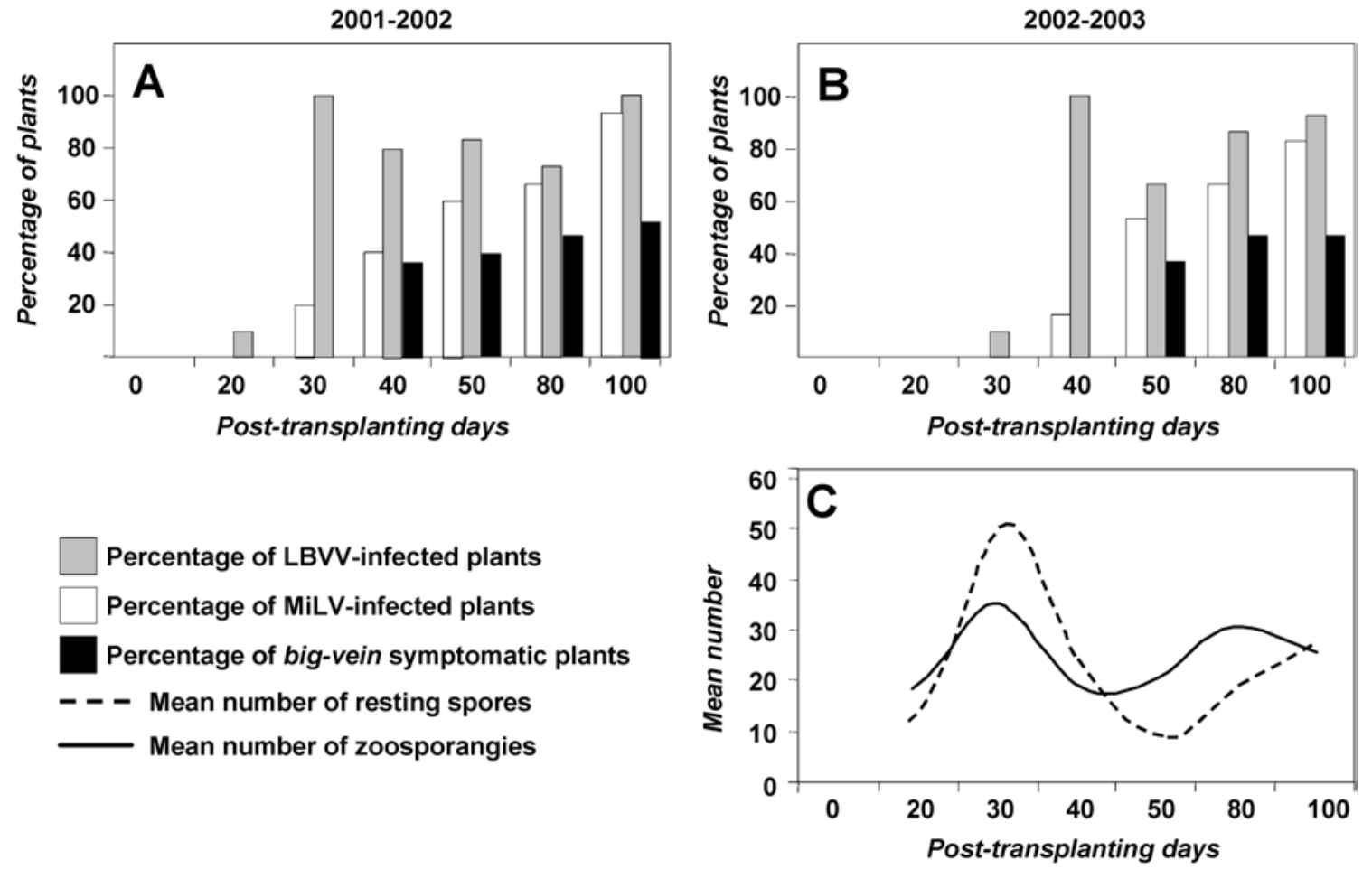

Fig. 4. Temporal analysis of Lettuce big-vein virus (LBVV) and Mirafiori lettuce virus (MiLV) in lettuce plants by nonisotopic molecular dot blot hybridization. Plants sampled were grown during the A, 2001 to 2002 and B, 2002 to 2003 production seasons in a commercial area (grupo PRIMAFLOR) with a known history of big-vein disease. Thirty lettuce plants were taken at each time point $(0,20,30,40,50,80$, and 100 days posttransplant). Vertical bars indicate the percentage of infected plants. White and gray bars indicate MiLV- or LBVV- infected plants, respectively. Percentage of symptomatic plants is shown as black bars. Olpidium brassicae infection was microscopically monitored in five 1-cm-long slices from lettuce roots per plant. $\mathbf{C}$, The infection was measured as the mean number of resting spores (broken line) and zoosporangia (continuous line) per centimeter. 
2002 to 2003 periods, respectively. The appearance of symptoms also was recorded because plants harboring the viruses may or may not express symptoms. No linear association between the spread of LBVV and obvious symptoms was observed $(r=0.49$; 2-tailed $p=0.32$ and $r=0.44$; 2-tailed $p=0.45$ for the comparison of LBVV infection progress with symptoms appearance for the 2001 to 2002 and 2002 to 2003 periods, respectively); meanwhile, a positive linear relationship was found between MiLV infection progress and the appearance of symptomatic lettuce plants $(r=0.93$; 2-tailed $p=0.0067$ and $r=0.97$; 2-tailed $p=$ 0.0072 for the 2001 to 2002 and 2002 to 2003 periods, respectively) (Fig. 4A and B). However, at the end of analyzed periods, all plants showing symptoms contained both viruses. Infection progress of $O$. brassicae in lettuce roots also was analyzed for the 2002 to 2003 period. In spite of the ability of this fungus to transmit both LBVV and MiLV to lettuce plants (11), a control experiment was performed to determine if Spanish isolates of this fungus also act as vector of the lettuce big-vein disease. Lettuce plants grown in sterilized soil developed big-vein symptoms when they were inoculated with $O$. brassicae zoospores isolated from roots of symptomatic lettuce plants. Infection progress analysis showed that at 30 days posttransplant, the fungus was present in most of the samples analyzed and achieved highest levels of zoosporangia and resting spores (Fig. 4C) coincident with detection of the first LBVV-infected plants. Between 30 to 50 days posttransplant, fungus presence was significantly diminished but later increased in a more progressive way, as did LBVV infection (compare Fig. 4B and C).

The reliability of these results was confirmed by multiplex RTPCR analysis of the 30 lettuce plants 50 days posttransplant for the 2002 to 2003 period (Fig. 5). Twenty-one lettuce plants showed the presence of at least one associated big-vein virus but only 11 samples clearly showed big-vein symptoms (Fig. 5, lower part). LBVV and MiLV infected 20 and 16 lettuce plants, respectively. Double infection was observed in 15 samples. Mixed infections were observed in all symptomatic plants, except one case in which only MiLV was detected.

\section{DISCUSSION}

In recent years, the sensitivity of plant virus detection in a great number of virus-host combinations has improved due to the use of nucleic acid-based techniques compared with serological techniques $(7-9,14,17,18,22-25)$. Indeed, such techniques are now considered reliable, fast, and inexpensive. However, molecular diagnosis of the viruses associated with lettuce big-vein disease previously has not been possible due to the lack of molecular characterization of the putative viruses responsible for the disease. Recently, the whole genome sequence of MiLV and the partial genome sequence of LBVV have been determined (26-28). This information allowed us to develop two molecular techniques for the detection of both viruses using a simple nucleic acid extraction method (1). Although the use of mixed riboprobes allows simultaneous detection of several viruses, individual virus identification is not possible in a dot blot format. A significant advantage of the multiplex RT-PCR followed by electrophoretic separation of the amplified products is the possibility of simultaneous detection and discrimination among two or more viruses in the same assay $(2,15,16,22)$. In this sense, we have adapted the RTPCR technology to detect LBVV and MiLV in the same reaction. In addition, we have included an RT-PCR internal control that uses an RNA template which flags potential false negatives caused by either RNA degradation or inhibition of RT-PCR. Thus, we designed a primer pair that allowed efficient annealing and partial amplification of the mitochondrial nad4 gene only after intron splicing (15). This gene from lettuce was selected as an internal control in our RT-PCR assays for three reasons: its sequence is available in the GenBank of the National Center for Biotechnology Information, it contains two exons separated by a 1,435-bp intron, and it is a gene involved in the basic metabolism of the plant.

Both strategies were successfully applied for detection of the two viruses associated with lettuce big-vein disease in naturally infected lettuce samples harvested from different production areas. Analysis of the distribution of virus in the plant showed

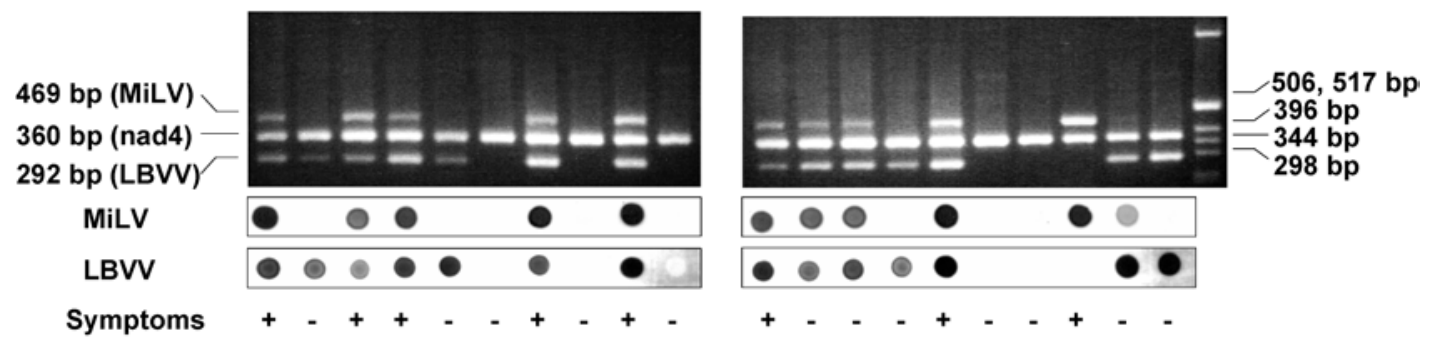

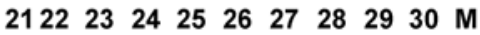

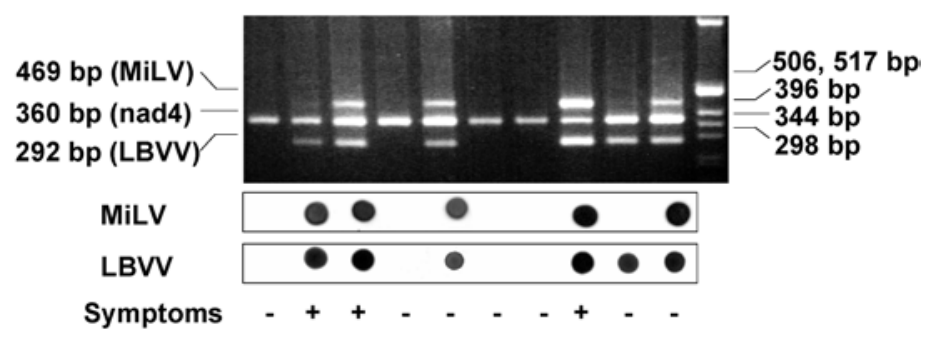

Fig. 5. Representative results for the detection of Lettuce big-vein virus (LBVV) and Mirafiori lettuce virus (MiLV) by multiplex reverse transcription-polymerase chain reaction (RT-PCR) and nonisotopic molecular dot blot hybridization. Analyzed samples corresponding to 30 samples obtained from a study of disease progress (50 days posttransplant for the 2002 to 2003 period). Results obtained by multiplex RT-PCR and dot blot hybridization are vertically located under the number for each lettuce plant analyzed. Virus names detected by cDNA amplification or hybridization signal are indicated on the left. Plants showing typical big-vein symptoms are marked as (+), whereas asymptomatic plants are marked as (-). Size of molecular marker bands (lane M) is shown on the left. 
that roots contain the highest concentration of LBVV. However, the necessity of additional steps to eliminate soil remains an impediment. The observation that in fully expanded leaves both viruses were equally detected led us to use this tissue as the preferred sample for routine diagnosis. Both detection methods rendered positive results for MiLV and LBVV in all sources and lettuce cultivars analyzed, confirming that big-vein disease is as widespread as previously reported (21). The results obtained from the analysis of serial dilutions of infected tissue preparations showed that nonradioactive dot blot hybridization was sensitive enough to detect LBVV, MiLV, or both at a tissue concentration of $156 \mu \mathrm{g} \mathrm{ml}^{-1}$, but was 33-fold less sensitive than the multiplex RT-PCR ( $4.8 \mu \mathrm{g}$ of tissue $\left.\mathrm{ml}^{-1}\right)$. Conversely, the former method is usually more laborious than serological analysis, because samples must be clarified by centrifugation to avoid unacceptable background signal, although this problem can be avoided without affecting the reliability of the method as reported previously (25).

Both LBVV and MiLV are transmitted by $O$. brassicae but probably do not replicate inside the vector (5). Thus, virus inoculum does not increase unless the fungus infects susceptible host cells. In this regard, crop rotation could represent a feasible measure of control. However, $O$. brassicae can infect a great variety of host plants including weeds, which may act as a reservoir. Moreover, virus survival is possible within the resting spores that can maintain a viruliferous state for decades (5). To correlate appearance of the disease or viruses with the presence of the fungus vector, a temporal analysis was carried out in a lettuce production area (Almería, Spain).

We demonstrated that just before or coincident with the first detection of big-vein-associated viruses in an unsterilized field, the largest number of resting spores per plant also occurred. This observation had been assumed (21) but not demonstrated previously. During this stage of infection, plants may or may not express symptoms depending on local factors such as temperature, luminosity, and soil condition (30). Moreover, the rate at which each virus spread was quite different, despite the fact that they are both transmitted by the same vector. LBVV and $O$. brassicae appeared to follow a similar infection pattern. The high LBVV dispersal that takes place initially (40 days posttransplant) is probably related to the early increase of $O$. brassicae (30 days posttransplant) observed in lettuce roots. It is tempting to speculate that the faster appearance of LBVV versus MiLV could be due to the higher viral concentration of LBVV in roots (described previously), which could facilitate systemic infection of leaves. The decrease in the percentage of LBVV-infected plants after 40 days posttransplant probably is related to the sampling method used. MiLV infection seems to be unrelated to the spread of its putative vector. Moreover, there is a high positive linear correlation between the appearance of symptoms and MiLV detection in plants, but this does not necessarily imply a cause-effect relationship. A common factor influencing increase of both variables with time also may result in a perfect correlation. Despite the different rates of virus infection, most lettuce plants were infected with both viruses after 100 days posttransplant, indicating the high transmission efficiency of both viruses and the importance of controlling fungus infection in the field. Similar results were obtained by Roggero et al. (20) although they used ELISA for virus detection and no information about vector infection was reported. In their study, LBVV but not MiLV was detected in two symptomatic lettuce plants, in disagreement with previous results that proposed MiLV as the causal agent of big-vein disease (13). However, as suggested by Roggero et al. (20), it is possible that ELISA was not sensitive enough to detect MiLV in low concentrations in these samples. In this sense, the use of alternative techniques such as dot blot hybridization or RT-PCR may resolve this issue.

\section{ACKNOWLEDGMENTS}

This work was supported by the European Commission under contract QLRT-1999-01471. We thank J. A. Sanchez-Navarro for critical reading of the manuscript and P. Thomas for checking the English grammar.

\section{LITERATURE CITED}

1. Astruc, N., Marcos, J. F., Macquaire, G., Candresse, T., and Pallás, V. 1996. Studies on the diagnosis of hop stunt viroid in fruit trees: Identification of new hosts and application of a nucleic acid extraction procedure based on non-organic solvents. Eur. J. Plant Pathol. 102:837-846.

2. Bertolini, E., Olmos, A., Martinez, M. C., Gorris, M. T., and Cambra, M. 2001. Single-step multiplex RT-PCR for simultaneous and colourimetric detection of six RNA viruses in olive trees. J. Virol. Methods 96:33-41.

3. Bos, L., and Huijberts, N. 1990. Screening for resistance to big-vein disease of lettuce (Lactuca sativa). Crop Prot. 9:446-452.

4. Campbell, R. N. 1965. Weeds as reservoir hosts of the lettuce big-vein virus. Can. J. Bot. 43:1141-1149.

5. Campbell, R. N. 1996. Fungal transmission of plant viruses. Annu. Rev. Phytopathol. 34:87-108.

6. Dellaporta, S., Woods, H., and Hicks, J. 1983. A plant DNA mini-preparation: Version II. Plant Mol. Biol. Rep. 1:19-21.

7. Fouly, H. M., Domier, L. L., and D’Arcy, C. J. 1992. A rapid chemiluminescent detection for barley yellow dwarf virus. J. Virol. Methods 39:291298.

8. Gosalvez, B., Navarro, J. A., Lorca, A., Botella, F., Sánchez-Pina, M. A., and Pallás, V. 2003. Detection of Melon necrotic spot virus in water samples and melon plants by molecular methods. J. Virol. Methods 113:87-93.

9. Habili, N., McInnes, J., and Symons, R. 1987. Non-radioactive, photobiotin-labelled DNA probes for the routine diagnosis of barley yellow dwarf virus. J. Virol. Methods 16:225-237.

10. Huijberts, N., Blystad, D. R., and Bos, L. 1990. Lettuce big-vein virus: Mechanical transmission and relationships to tobacco stunt virus. Ann. Appl. Biol. 116:463-475.

11. Kawazu, Y., Sasaya, T., Morikawa, T., Sugiyama, K., and Natsuaki, T. 2003. Nucleotide sequence of the coat protein gene of Mirafiori lettuce virus. J. Gen. Plant Pathol. 69:55-60.

12. Kuwata, S., Kubo, S., Yamashita, S., and Doi, Y. 1983. Rod-shaped particles, a probable entity of lettuce big-vein virus. Ann. Phytopathol. Soc. Jpn. 49:246-251.

13. Lot, H., Campbell, R. N., Souche, S., Milne, R. G., and Roggero, P. 2002. Transmission by Olpidium brassicae of Mirafiori lettuce virus and Lettuce big-vein virus, and their roles in lettuce big-vein etiology. Phytopathology 92:288-293.

14. Más, P., Sánchez-Navarro, J. A., Sánchez-Pina, M. A., and Pallás, V. 1993. Chemiluminescent and colorigenic detection of cherry leaf roll virus with digoxigenin-labeled RNA probes. J. Virol. Methods 45:93-102.

15. Menzel, W., Jelkmann, W., and Maiss, E. 2002. Detection of four apple viruses by multiplex RT-PCR assays with coamplification of plant mRNA as internal control. J. Virol. Methods 99:81-92.

16. Nassuth, A., Pollari, E., Helmeczy, K., Stewart, S., and Kofalvi, S. A. 2000. Improved RNA extraction and one-tube RT-PCR assay for simultaneous detection of control plant RNA plus several viruses in plant extracts. J. Virol. Methods 90:37-49.

17. Pallás, V., Más, P., and Sánchez-Navarro, J. A. 1998. Detection of plant RNA viruses by non-isotopic dot-blot hybridisation. Pages 461-468 in: Plant Virus Protocols: From Virus Isolation to Transgenic Resistance. G. Foster and S. Taylor, eds. Humana Press, Totowa, NJ.

18. Pallás, V., Sánchez-Navarro, J. A., Más, P., Cañizares, M. C., Aparicio, F., and Marcos, J. F. 1998. Molecular diagnostic techniques and their potential role in stone fruit certification schemes. Options Méditerr. 19: 191-208.

19. Roggero, P., Ciuffo, M., Vaira, A. M., Accotto, G. P., Masenga, V., and Milne, R. G. 2000. An Ophiovirus isolated from lettuce with big-vein symptoms. Arch. Virol. 145:2629-2642.

20. Roggero, P., Lot, H., Souche, S., Lenzi, R., and Milne, R. G. 2003. Occurrence of Mirafiori lettuce virus and Lettuce big-vein virus in relation to development of big-vein symptoms in lettuce crops. Eur. J. Plant Pathol. 109:261-267.

21. Ryder, E. J., and Robinson, B. J. 1995. Big-vein resistance in lettuce: Identifying, selecting, and testing resistant cultivars and breeding lines. J. Am. Soc. Hortic. Sci. 120:741-746.

22. Saade, M., Aparicio, F., Sánchez-Navarro, J. A., Herranz, M. C., Myrta, A., Di Terlizzi, B., and Pallás, V. 2000. Simultaneous detection of the three ilarviruses affecting stone fruit trees by nonisotopic molecular hybridization and multiplex reverse-transcription polymerase chain reaction. Phytopathology 90:1330-1336. 
23. Sánchez-Navarro, J. A., Aparicio, F., Rowhani, A., and Pallás, V. 1998. Comparative analysis of ELISA, nonradioactive molecular hybridization and PCR for the detection of prunus necrotic ringspot virus in herbaceous and Prunus hosts. Plant Pathol. 47:780-786.

24. Sánchez-Navarro, J. A., Cañizares, M. C., Cano, E. A., and Pallás, V. 1999. Simultaneous detection of five carnation viruses by non-isotopic molecular hybridization. J. Virol. Methods 82:167-175.

25. Sánchez-Navarro, J. A., Cano, E. A., and Pallás, V. 1996. Non-radioactive molecular hybridization detection of Carnation mottle virus in infected carnations and its comparison to serological and biological techniques. Plant Pathol. 45:375-382.

26. Sasaya, T., Ishikawa, K., and Koganezawa, H. 2001. Nucleotide sequence of the coat protein gene of Lettuce big-vein virus. J. Gen. Virol. 82:15091515 .
27. Sasaya, T., Ishikawa, K., and Koganezawa, H. 2002. The nucleotide sequence of RNA1 of Lettuce big-vein virus, genus Varicosavirus reveals its relation to nonsegmented negative-strand RNA viruses. Virology 297:289-297.

28. van der Wilk, F., Dullemans, A. M., Verbeek, M., and van den Heuvel, J. F. 2002. Nucleotide sequence and genomic organization of an ophiovirus associated with lettuce big-vein disease. J. Gen. Virol. 83:28692877.

29. Vetten, H. J., Lesemann, D. E., and Dalchow, J. 1987. Electron microscopical and serological detection of virus-like particles associated with lettuce big-vein disease. J. Phytopathol. 120:53-59.

30. Walsh, J. A. 1994. Effects of some biotic and abiotic factors on symptom expression of lettuce big-vein virus in lettuce (Lactuca sativa). J. Hortic. Sci. 69:21-28. 